\title{
UM CENÁRIO SOBRE A UTILIZAÇÃO DE REALIDADE VIRTUAL EM UMA INSTITUIÇÃO DE ENSINO.
}

\author{
Fabio Fonseca Barbosa Gomes ${ }^{1}$ \\ https://orcid.org/0000-0001-5113-9553 \\ Éricles Alberto de Jesus Ribeiro ${ }^{2}$ \\ https://orcid.org/0000-0002-6820-2456
}

\section{RESUMO}

Recebido: 02.07.2020

Aceito: 28.11 .2020

Publicado: 15.01.2021

Atualmente, a tecnologia de realidade virtual vem sendo cada vez utilizada, visto que suas aplicações são diversas e possuem um potencial incrível a longo prazo, podendo ser inserido na educação, saúde, militar, entre outros. $\mathrm{Na}$ área de Educação, a Realidade virtual traz um novo conceito, pois fomenta a interação do aluno com o conteúdo, trazendo uma maior imersão e possível aumento do potencial de ensino e aprendizagem do discente. Portanto, o objetivo deste trabalho é identificar o que o público de uma instituição de ensino pensa sobre o uso de uma tecnologia de realidade virtual sendo utilizada durante as aulas. Para atingir esta meta, foi feita uma pesquisa de forma aleatória com 80 alunos entre 15 e 30 anos em uma instituição de ensino de Salvador, Brasil. Eles responderam a um questionário que contava com informações sobre o uso de tecnologias de realidade virtual. Os resultados mostraram que pouco mais da metade destes alunos informaram que não estão motivados com a forma tradicional de dar aula, com o professor explicando em sala e o aluno ouvindo e que achariam interessante o incremento de uma solução que permitisse uma maior interação deles com o conteúdo. Assim, concluiu-se que os alunos estão começando a se acostumar com o uso de tecnologias da informação de Realidade Virtual nas salas de aula. Para realizar esta pesquisa, foram de grande importância a leitura dos trabalhos de diversos autores, incluindo Aureliano et al. (2019), Giassi e Ramos (2016), Oliveira et al. (2020) e Ying et al. (2017).

Palavras-Chave: realidade virtual; informática; ensino.

\section{Escenario de utilización de realidad virtual en una institución educativa}

\section{RESUMEN}

Actualmente, la tecnologia de realidad virtual esta siendo cada vez mas utilizada, debido a sus aplicaciones diversas y su potencial a largo plazo, pudiendo ser insertado en sectores como educación, salud, milicia, entre otros. En el area educativa, la realidad virtual trajo un nuevo concepto, pues fomenta la interacción del alumno con el contenido, trayendo una mayor inmersión y posible aumento del potencial de enseñanza y aprendizaje del alumno. Por tanto, el objetivo de este trabajo es identificar lo que el publico de una institucion educativa piensa sobre el uso de una tecnologia de realidad virtual en las aulas. Para lograr la meta fue hecha una investigacion de forma aleatoria con 80 alumnos entre 15 y 30 años en una institución de enseñanza de Salvador, Brasil. Ellos respondieron un cuestionario que contaba con informaciones sobre el uso de la tecnologia de realidad virtual. Los resultados muestran que poco más de la mitad de los alumnos informaron que no estan motivados con la forma tradicional del aula, con el profesor explicando en sala o el alumno escuchando y que hallaban interesante el incremento de este tipo de actividades que permiten una mayor interaccion con el contenido. Concluyendo que los alumnos estan comenzando a acostumbrarse con el uso de tecnologias de información de realidad virtual en las aulas de clase. Para realizar esta investigación fueron de gran importancia la lectura de trabajos de diversos autores, incluyendo Aureliano et al. (2019), Giassi y Ramos (2016), Oliveira et al. (2020) y Ying et al. (2017).

Palabras clave: realidad virtual; informatica; enseñanza.

\section{A Scenario on the Use of Virtual Reality in an Educational Institution}

\section{ABSTRACT}

Currently, virtual reality technology has been increasingly used, since its applications are diverse and have incredible long-term potential, which can be inserted in education, health, military, among others. In the area of Education, Virtual Reality brings a new concept, as it fosters student interaction with the content, bringing greater immersion and

\footnotetext{
${ }^{1}$ Bacharelado em Sistemas de Informação e mestrado em Sistemas e Computação. Atualmente é professor mestre do Centro Universitário Regional do Brasil, professor horista do Centro Universitário Dom Pedro II, professor assistente na Escola Bahiana de Medicina e Saúde Pública e professor mestre na Fundação Visconde de Cairu. E-mail: fabiofbg@gmail.com

2 Tecnólogo em Análise e Desenvolvimento de Sistemas. E-mail: ericles00@hotmail.com
} 
possible increase in the student's teaching and learning potential. Therefore, the objective of this work is to identify what the public of an educational institution thinks about the use of a virtual reality technology being used during classes. In order to achieve this goal, a random survey was carried out with 80 students between 15 and 30 years old in an educational institution in Salvador, Brazil. They answered a questionnaire that had information about the use of virtual reality technologies. The results showed that just over half of these students reported that they are not motivated by the traditional way of teaching, with the teacher explaining in class and the student listening and that they would find it interesting to increase a solution that would allow them to interact more with the teacher. content. Thus, it was concluded that students are starting to get used to the use of Virtual Reality information technologies in classrooms. In order to carry out this research, it was of great importance to read the works of several authors, including Aureliano et al. (2019), Giassi and Ramos (2016), Oliveira et al. (2020) and Ying et al. (2017).

Keywords: virtual reality; education; teaching.

\section{Introdução}

A evolução das tecnologias baseada no processamento de dados foi rápida e eficiente em poucas décadas existência. Atualmente, a realidade virtual (RV) vem sendo aplicada em diversas vertentes da sociedade e isso permitiu a geração de novos avanços nessas áreas. (Giassi e Ramos, 2016). Uma dessas áreas é a Educação que, de acordo com Oshima (2016, p. 1), "é um dos principais horizontes da realidade virtual. A imersão que ambientes virtuais propiciam pode reproduzir vivências e facilitar a compreensão - e a apreensão - de conceitos de forma muito mais eficiente do que a teoria pura".

O incremento desta tecnologia serviria para tornar as aulas dos estudantes mais interativas em interessantes. Em muitos casos, o estudante de uma instituição de ensino tem dificuldades com o estilo de aula tradicional, em que o aluno apenas escuta a explicação do professor. A RV surge como um meio para tornar esta aula mais inspiradora e motivante, servindo como um complemento às explicações dadas ao docente. Também dá ao aluno a possibilidade de ver e interagir com objetos referente ao assunto que o professor está explicando, como visitar a Roma antiga virtualizada, em pleno século I, por exemplo através de óculos de RV.

Isso mostra como a RV um papel significativo na educação e que, soluções nesta área seriam de grande contribuição para a sociedade. Portanto, este artigo tem como objetivo principal apresentar um cenário mostrando o que os alunos de uma instituição de ensino acham sobre a utilização de ferramentas de RV durante as aulas, nas salas. Para chegar a tais objetivos será dado enfoque aos benefícios da realidade virtual aplicada em aulas de manutenção de microcomputadores, como funcionam os dispositivos de VR (Virtual Reality - Realidade Virtual) e arquitetura.

O artigo está dividido da seguinte forma: (i) a seção 2 irá abordar os conceitos referentes a hipermídia; (ii) a seção 3 irá apresentar conceitos sobre realidade virtual e seu funcionamento; (iii) a seção 4 irá se debruçar sobre o uso da realidade virtual nas aulas de informática, além de uma pesquisa sobre o tema com os alunos de uma instituição de ensino localizada na cidade de Salvador, Brasil e (iv) a seção 5 está reservada para as considerações finais.

\section{Hipermídia}

Para Babbitt et al. (1993), a hipermídia é um tipo de veículo que ajuda a passar a informação de um jeito não convencional. Para Ramos (2019), nas instituições de ensino, em geral, professores ministram aulas de forma direta, ou seja, os eles abordam o conteúdo sem a interação com os alunos, que apenas ouvem, sem poder opinar. Normalmente, em situações desse tipo, os discentes armazenam aquelas situações e informações por um período breve, mas depois começam a se esquecer od conteúdo dado pelo docente. "O avanço da ciência e da tecnologia não é tarefa de demônios, mas sim a expressão da criatividade humana. Por isso as recebo da melhor forma possível” [Martini, 2001].

"A hipermídia é um ambiente ideal para auxiliar os estudantes a estabelecerem conexões entre os assuntos estudados, pois possibilita criar facilmente ligações entre conceitos, definições, representações e aplicações relacionadas, ampliadas com a adição de som, movimento e gráficos” 
[Babbitt et al., 1993, p. 28]. Desta forma, compreende-se que o uso da hipermídia faz com que as informações sejam passadas de forma diferente, o que era para ser apenas algumas linhas em uma folha se tornam imagens, sons, expressões, ações. Isso causa impacto não somente nas escolas, mas também na vida cotidiana, a hipermídia está inclusa em tudo.

Folhetos, cartazes e livros passam a ter uma versão um pouco diferente, evoluída, uma versão mais de acordo com a atualidade. A hipermídia então se trata de uma remodelagem do ato de passar informações para que elas não somente sejam passadas, mas também sejam lembradas. Outro caso sobre o uso da hipermídia pode ser visto na Times Square, em Nova York, nos Estados Unidos da América, onde os prédios ficam repletos de imagens e vídeos querendo emitir suas mensagens de consumo ou mesmo notícias conforme pode ser visto na figura 1.

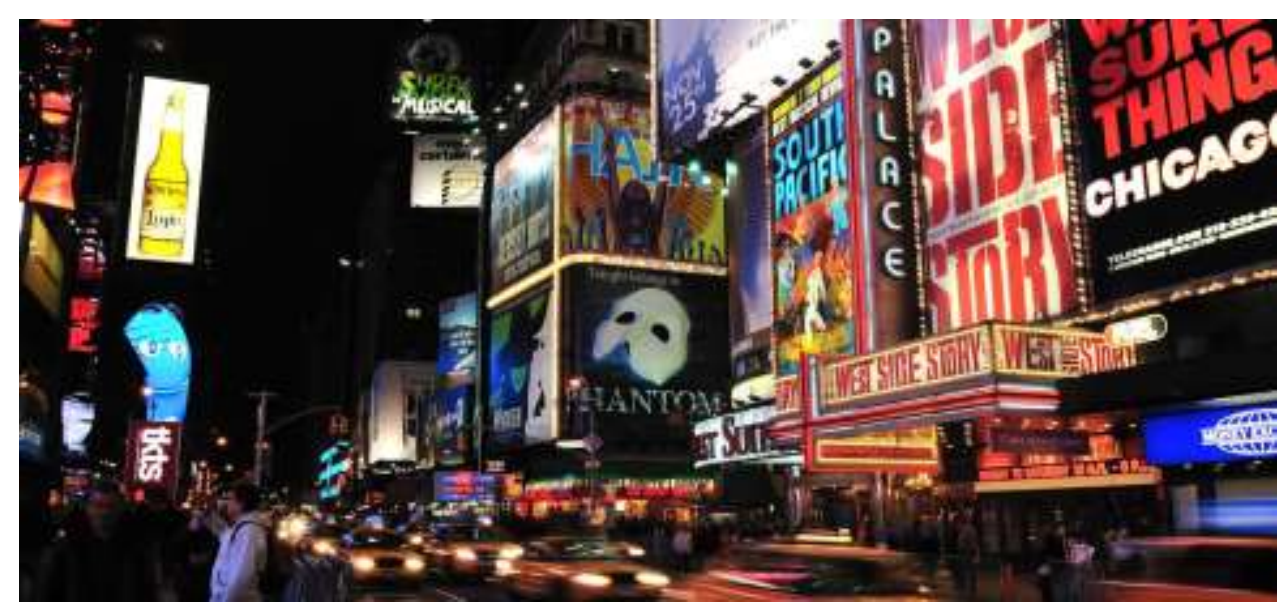

Figura 1: Time Square, Cidade de Nova York

Fonte: Renaissance Hotels (2020)

\section{Realidade Virtual}

A realidade virtual é uma tecnologia com interface capaz de enganar os sentidos de uma pessoa tornando o ambiente criado através de um computador mais realista ou mesmo agradável. Porém, para melhorar esta distorção da realidade são necessários estímulos visuais e auditivos que fazem com que aquele som emitido e aquela imagem vista sejam reais perante o cérebro, se tornando uma outra realidade perante os sentidos [Dores et al., 2012].

O antecessor dos dispositivos de realidade virtual foi o estereoscópico, criado pelo físico Sir Charles Wheatstone em 1838 [Pereira e Nogueira, 2018]. Após isso, outros dispositivos foram criados como o Sensorama, que colocava em prática a questão da distorção dos sentidos com uma tela 3D com som e sensações como brisa do vento e aromas. Após diversas tentativas da imersão em meios diferentes, a realidade virtual foi para os games na década de 1990. Vários dispositivos foram criados como: o Sega VR, Virtuality Pod, e o Nintendo Virtual Boy até chegar na atualidade e a evolução começar a tomar um rumo definitivo.

\section{Funcionamento de um dispositivo de realidade virtual}

Um dispositivo de realidade virtual funciona através de lentes para criar um ponto focal e dar a sensação de profundidade. As lentes apresentadas nos óculos 3D servem para dar uma sensação mais real para o usuário, simulando a visão binocular que se está habituado. Sistemas de detecção de movimentos (giroscópio e bússola) são colocados para dar a impressão de movimento e acompanhar a rotação do corpo e visão, assim como áudio 3D e sistema de posicionamento para produzir os sons de ambos os lados, assim como o volume, e o movimento da cabeça, conforme pode ser visto através da figura 2 deste trabalho. 


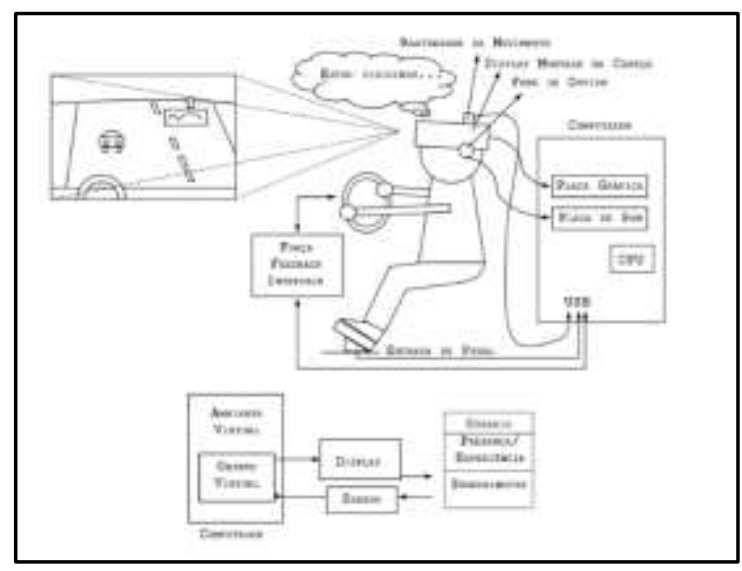

Figura 2: Partes de um dispositivo de realidade virtual

Fonte: Pereira e Nogueira (2018)

Em 13 de outubro de 2016, a Sony anunciou o Playstation VR que insere a tecnologia de realidade virtual dentro dos jogos do console, expandindo horizontes e criando uma realidade dentro de seus jogos. Mostrou que é possível aperfeiçoar essa tecnologia e que isso pode ter um impacto enorme na sociedade, com aplicações diversas, a realidade virtual pode ser incluída nas escolas, melhorando o aprendizado, em hospitais, melhorando a precisão de exames com a virtualização do corpo do paciente e até no treinamento militar, evitando acidentes.

\section{A Realidade Virtual nas Aulas de Informática}

A realidade virtual, vem se tornando bastante popular, por se tratar de uma ferramenta que gera interação do aluno com o conteúdo, "a realidade virtual e aumentada, percebemos que ela se encontra em franca expansão no ambiente escolar, possibilitando ao aluno descobrir, explorar e construir seu próprio conhecimento" [Filho e Dias, 2019]. Em muitas áreas a realidade virtual é vista como algo futurista que pode mudar tudo, inclusive na educação. Várias escolas brasileiras incorporam programas de realidade virtual em seu planejamento de aula (figura 3), mudando a perspectiva do aluno. Porém, um dos grandes empecilhos para que isto se torne algo maior é o custo.

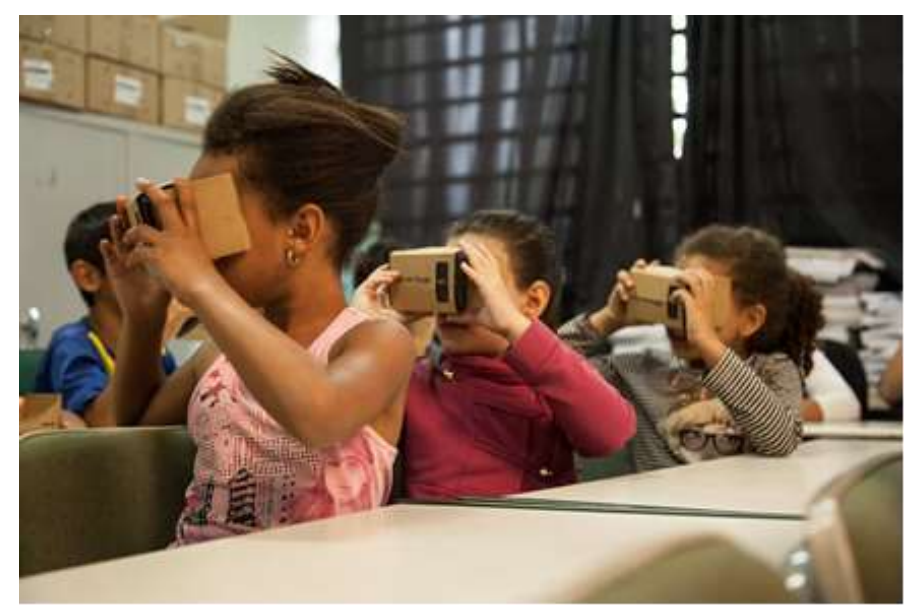

Figura 3: Alunos da Escola Estadual Santa Rosa de Lima, São Paulo

Fonte: Oshima (2016)

Para Oshima (2016), a viabilidade econômica da realidade virtual não facilita a inclusão pedagógica. Mas, existem recursos que podem ser viáveis e ainda de fácil acesso com um celular em mãos. Nas aulas de informática pode parecer inviável a inclusão da realidade virtual, mas simuladores pré- 
programados podem criar um mundo de infinitas possibilidades. Situações em que antes eram apenas gráficos e imagens em um slide se tornam objetos virtuais de fácil manuseio e com maior interação.

O ser humano é um ser tecnológico e como tal, busca sempre a superação. Como cita Sancho [1998, p.28 apud Zampier, 2016, p.09], "a tecnologia existe para auxiliar a resolver problemas e desta maneira todo indivíduo é produtor e consumidor de tecnologia e essa é, basicamente, uma produção humana".

\section{O uso da Realidade Virtual em uma disciplina da área de informática}

A utilização de computadores faz parte da rotina diária das empresas, porém estes dispositivos computacionais podem ter problemas físicos ou lógicos. Para cobrir esses danos é necessária a formação de profissionais capacitados para dar o devido suporte e manutenção aos computadores. Para compreender os conceitos relativos à manutenção de equipamentos, é necessário conhecer um computador. Conforme foi afirmado por Freire (2001), pelo método tradicional de ensino, pode ser desconfortável ao aluno ter um único método como o tipo de aula tradicional, em que o professor fala apenas sobre as placas e como consertá-las e o aluno ouve. Caso não seja possível realizar aulas práticas, por questão de custos, o uso da realidade virtual pode se tornar uma solução para este problema.

O exemplo apresentado na figura 4 é um simulador de manutenção de computadores, no qual o aluno tem a capacidade de montar todo o computador através do computador, ele funciona como se fosse um jogo, interagindo com o usuário e simulando o funcionamento da máquina [Cisco, 2018].

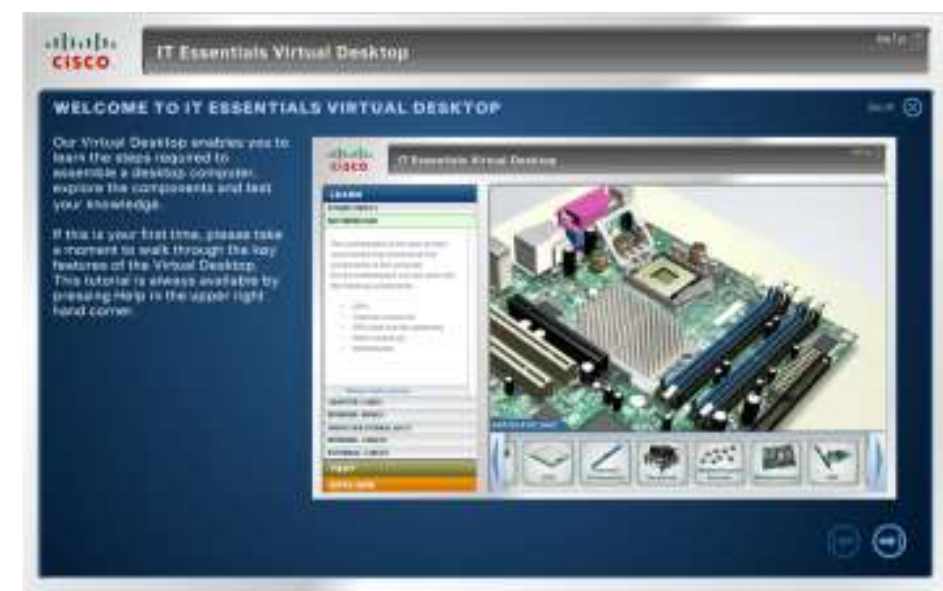

Fonte: Cisco (2018)

Figura 4: Placa mãe de um computador

Utilizando a solução vista na figura 4 com uma ambientação 3D seria ainda mais interessante para o aluno, que poderia até se locomover virtualmente dentro da placa com o uso de dispositivos como o uso da tecnologia de óculos 3D, conforme pode ser visto na figura 5. 


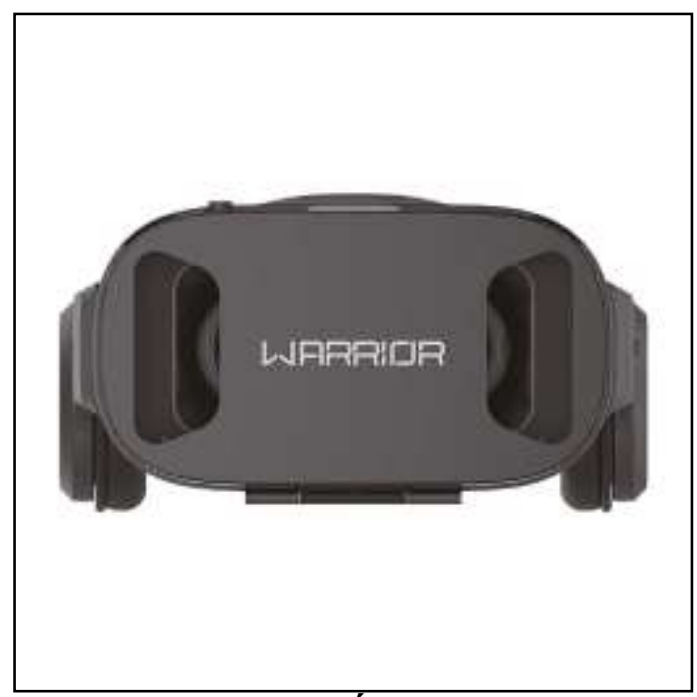

Fonte: Multilaser (2019)

Figura 5: Óculos 3D

Ying et al. (2017) produziram uma solução chamada VREX (Virtual Reality based Education eXpansion - Realidade Virtual baseada em Expansão da Educação) que tem como principal objetivo facilitar o ensino e aprendizagem dos alunos. Segundo os autores, esta solução trouxe uma grande imersão aos alunos, consequentemente eles conseguiram aprender o conteúdo de forma mais prática e prazerosa.

As soluções apresentadas anteriormente podem mostrar que a realidade virtual pode aumentar o interesse dos alunos pelo tema, inserindo-os em um mundo novo, onde pudessem ver cada parte de um sistema ou hardware de uma forma diferente, saindo do modelo comum que seriam papéis e slides e entrando um mundo simulado. Assim como simuladores já são inseridos em áreas como a medicina e até em algumas autoescolas, não seria diferente para as aulas de manutenção de micro. Cada peça de um monitor, processador, teclado ou qualquer outro hardware explicada e simulada em detalhes em frente aos olhos, criando um mundo de oportunidades e aprendizado. "As simulações são bastante fiéis aos principais sentidos do ser humano: espacial, visual, auditivo e tátil" [Kochhann, 2019].

Para desenvolver as soluções vistas anteriormente, faz-se uso de diversas ferramentas de modelagem, que tem a capacidade de desenvolvimento de soluções que podem ser utilizadas pela realidade virtual. Ferramentas como Blender e Unity conseguem fazer a modelagem de qualquer objeto através de eixos e escalas que dão forma. Estes elementos são construídos com uma grande riqueza de detalhes, que garantem determinada empatia e semelhança com o mundo real e sua facilidade de criação os torna imprescindíveis em qualquer projeto que envolva modelagem 3D.

Aplicando estes conceitos em um simulador de microcomputadores 3D, percebe-se que as interações dos alunos com o sistema seriam extremamente detalhadas e coordenadas, para passar uma sensação mais real aos alunos. O VR passa a sensação para o usuário de estar em um mundo alternativo, mas com características reais e convincentes. Outras ferramentas como o Blocks, lançado pela Google, oferecem aos alunos uma forma deles mesmos modelarem dentro da realidade virtual, sem necessitar de outras ferramentas ou aparelhos [Kochhann, 2019].

\section{Pesquisa sobre opinião pública}

Foi feita uma pesquisa de campo com 80 alunos (com a faixa de idade entre 15 e 30 anos) em uma instituição de ensino localizada na cidade de Salvador, estado da Bahia, Brasil. O método de escolha dos alunos foi aleatório e anônimo na instituição de ensino. O objetivo desta exploração foi saber como o aluno acha que se comportaria com o uso de tecnologia de RV na sua instituição de ensino. Para a análise quantitativa, foram levantadas as seguintes perguntas vistas na tabela 1: 
Tabela 1. Questões utilizadas na pesquisa de campo

\begin{tabular}{|c|l|}
\hline Número & \multicolumn{1}{|c|}{ Pergunta } \\
\hline 1 & Está satisfeito como suas aulas são ministradas? \\
\hline 2 & Como gostaria que suas aulas fossem ministradas? \\
\hline 3 & Como se sentiria se suas aulas fossem ministradas através do VR? \\
\hline 4 & $\begin{array}{l}\text { Acha que a realidade virtual poderia mudar a forma com que se assiste às } \\
\text { aulas? }\end{array}$ \\
\hline
\end{tabular}

Fonte: Autoria Própria

Em relação as respostas das perguntas feitas na tabela 1 foram utilizadas algumas opções de respostas que o aluno deveria escolher. Para uma maior variedade de opiniões os participantes foram escolhidos através da técnica de Amostragem Aleatória Simples (AAS) na instituição de ensino [Bolfarine, e Bussab, 1994]. As perguntas eram de caráter objetivo e foi realizada de forma individual. Os resultados coletados podem ser vistos através das figuras $6,7,8$ e 9, cada uma das figuras contém uma das perguntas e as possíveis respostas dos usuários.

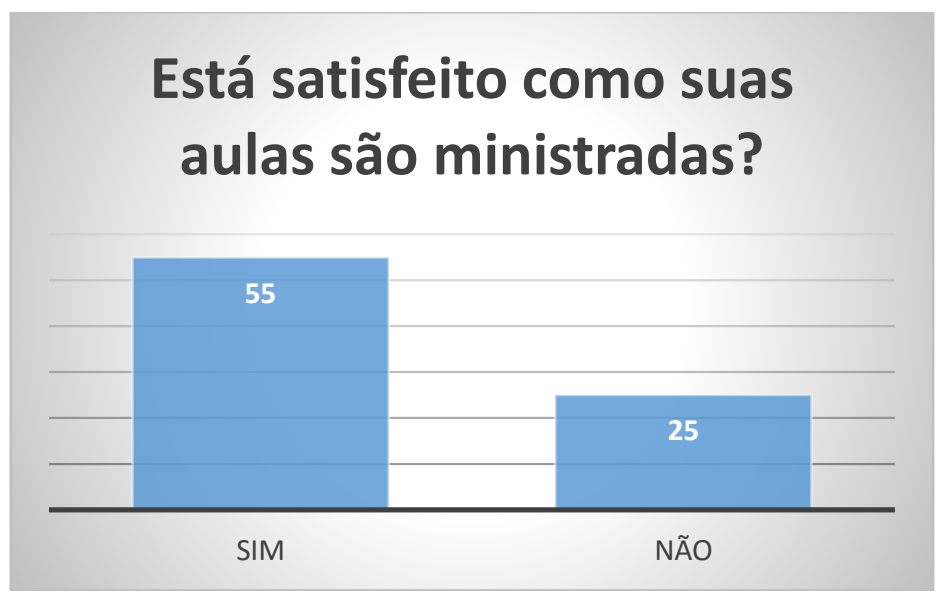

Figura 6: Satisfação do aluno em relação as suas aulas em sala

Fonte: Autoria Própria

$\mathrm{Na}$ figura 6, a primeira questão informava sobre a satisfação em respeito de como as aulas são ministradas na escola. Perguntou-se sobre a satisfação deles sobre a forma que os professores ministravam o conteúdo em sala. 55 participantes se mostraram insatisfeitos com a forma de aula dada pelo docente, enquanto 25 achava as aulas satisfatórias.

Um exemplo do bom uso desta tecnologia é na área de educação médica, pode-se perceber que o aluno participa mais das atividades, agregando ainda mais experiência ao seu conhecimento. " $\mathrm{Na}$ educação médica cirúrgica dos países desenvolvidos, a RV tem sido empregada no ensino de anatomia e na simulação de operações, principalmente para o treinamento operatório de cirurgia video-laparoscópica, no planejamento pré-operatório e no suporte intraoperatório" [Montero e Zanchet, 2003].

$\mathrm{Na}$ vista na figura 7 , os candidatos deveriam dizer como gostariam que suas aulas fossem ministradas e 58 participantes preferiam aulas utilizando realidade virtual, 10 preferiam aulas mais tradicionais ministradas através de quadro branco ou slides e os outros 12 aderiam às aulas através da pura leitura. 


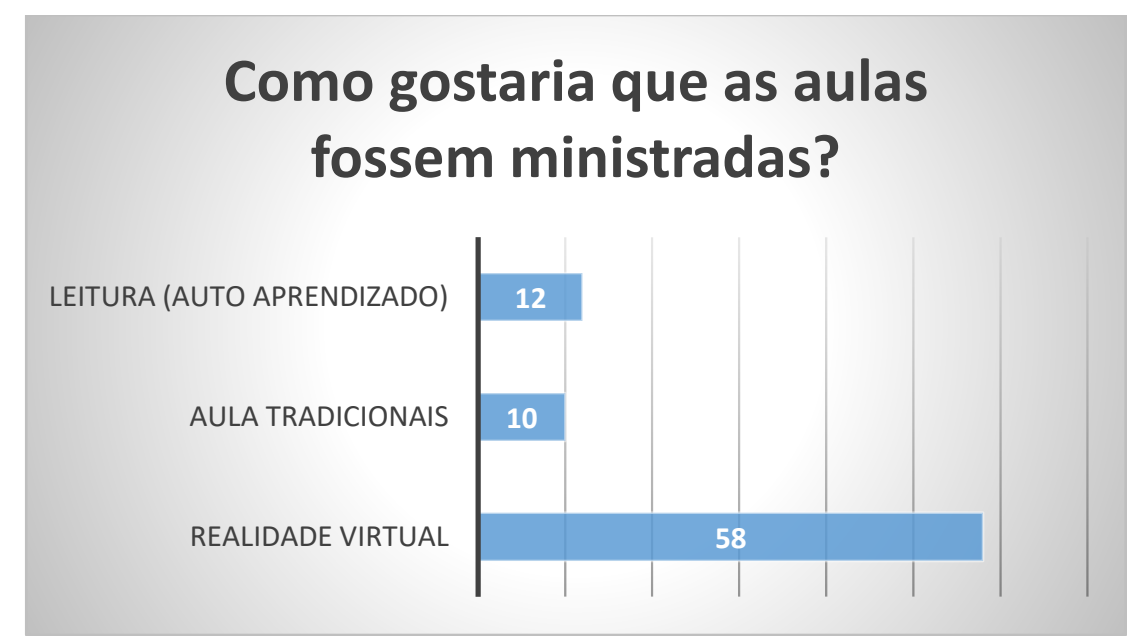

Fonte: Autoria Própria

Figura 7: Tecnologias nas aulas

O fato interessante na figura 7 é que a grande maioria prefere um sistema de realidade virtual em salas de aula. Isto tem um fator neurológico a favor, o ser humano é muito visual, entende melhor uma imagem ou um vídeo sobre um tema do que um conjunto de palavras, ou seja, "a visão é o nosso sentido primário e usa quase $50 \%$ do córtex do cérebro. Este fato tem sido esquecido por educadores durante séculos em favor de uma abordagem essencialmente baseada na fala e no texto abordagem à aprendizagem.” [Lockwood, 2004].

Ainda segundo Lockwood (2004), isto demonstra que existe uma necessidade de mudança na memorização de fatos, para atingir uma maior capacidade cognitiva, visto que o cérebro consegue armazenar de forma mais eficiente o contexto de uma determinada situação, quando imagens sobre isto estão disponíveis.

É importante salientar que o uso da RV deve ser um complemento ao ensino já existente e que o objetivo não é substituir o ensino tradicional completamente. Desta forma, entende-se que a tecnologia não deve ser usada a todo o momento no processo de ensino e aprendizagem, ou seja, "não se trata de erradicar o quadro negro e o lápis da sala de aula" [Aureliano et al., 2019].

$\mathrm{Na}$ figura 8 foi realizado o questionamento: "Como se sentiria se as aulas passassem a ser ministradas através do VR?”. Desta forma, dos 80 participantes, 30 se mostraram estar nervosos e receosos sobre o que fariam se suas aulas passassem a serem realizados com a ajuda da realidade virtual, 23 se mostraram indiferentes e 27 apresentaram-se empolgados com esta possibilidade.

Este pode ser um fator impulsionador para o uso desta mesma tecnologia me outras áreas da sociedade, como o caso da Indústria 4.0 ou indústria inteligente. No contexto educacional, o termo é chamado de Educação 4.0, em que o uso das tecnologias da informação serão uma ferramenta eficaz no ensino e aprendizagem, "esses jovens alunos que receberão uma Educação 4.0 terão em sua formação integral a capacidade de pensar criativamente para propor projetos e de resolver problemas" [Aureliano et al., 2019]. 


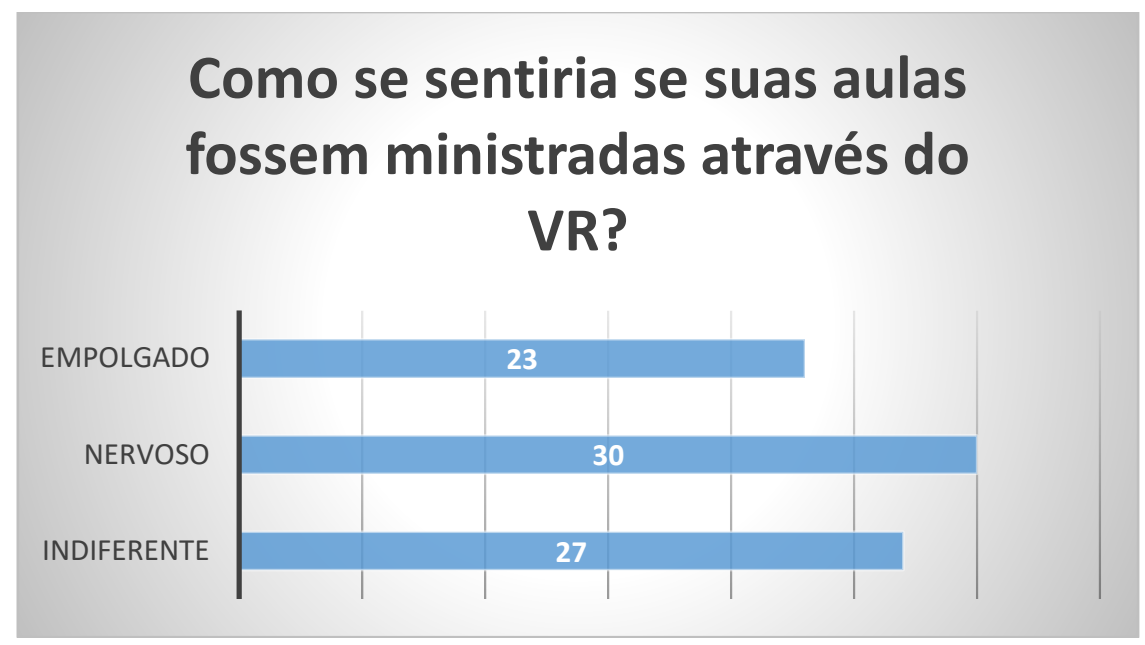

Figura 8: Sensação do aluno nas aulas com RV

Fonte: Autoria Própria

Observando a figura 9, ao responder à pergunta: "Acha que a realidade virtual poderia mudar a forma com que se assiste às aulas?", 60 participantes acham que as aulas iriam mudar de alguma forma, enquanto 20 participantes responderam que não mudaria muito. Conforme os dados coletados, percebeu-se que muitos participantes acham que a tecnologia de RV poderia tornar as aulas mais interessantes, mudando a forma de assistir as aulas.

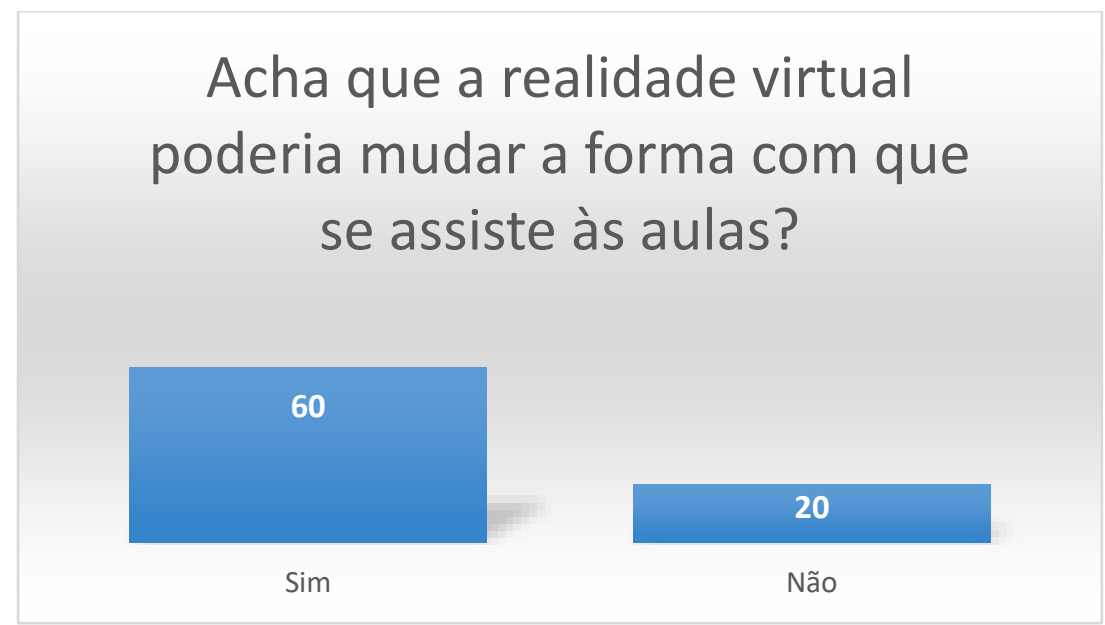

Figura 9: Realidade Virtual nas aulas de informática

Fonte: Autoria Própria

Analisando os gráficos apresentados nas figuras anteriores, percebe-se que os alunos estão começando a se acostumar com o uso de tecnologias da informação nas salas de aula e que as aulas tradicionais irão, cada vez mais, dividir o espaço com elas. Segundo Ribeiro e Lopes (2019), boa parte dos professores estão começando a introduzir diversas tecnologias da informação da sala.

Para que isto seja possível "as ferramentas de VR também precisam estar alinhadas ao planejamento pedagógico para que seu uso não seja meramente recreativo.” [Kochhann, 2019]. Desta forma, compreende-se que o uso da tecnologia de realidade virtual deve ser utilizado de forma responsável e planejada, para que não ocorra uma perda de foco do aluno no conteúdo da aula.

Um aspecto que está ajudando a impulsionar a utilização desta tecnologia em muitas instituições de ensino é a pandemia de COVID19, que iniciou no ano de 2020. Isto está fazendo com que 
algumas instituições de ensino identificaram que a única opção para manter os alunos na instituição, é aderir a tecnologias como a RV e ferramentas EAD, que além de manter o aluno interessado na disciplina, faça-o aprender.

$\mathrm{Na}$ Índia, com uma população de mais de 1 bilhão de pessoas, a adoção de tecnologias voltadas ao ensino vem se mostrando resultados inspiradores [Wadhwa, Khatak e Poonam, 2020]. Então o uso de tecnologias de RV em disciplinas ministradas a distância passa a ser uma opção válida para o ensino e aprendizagem. "Certamente os recursos que foram investidos em tecnologias para ofertar o ensino online e remoto durante o período de quarentena, serão expandidos e assimilados no retorno as aulas presenciais" [Oliveira et al., 2020].

Apesar das grandes vantagens Afonso et al. (2020) abordam que o uso desta tecnologia deve ser feito com cautela e prudência, pois seu uso em excesso pode causar tontura, náuseas e outros problemas a saúde humana. "Nessa perspectiva, a conscientização para o uso eficaz da ferramenta é fundante para que os usuários dos equipamentos não sejam acometidos de cyber doenças, como dependência do uso do equipamento, bem como, por exemplo, danos à saúde como náuseas, tonturas, entre outros sintomas".

\section{Considerações finais}

A realidade virtual se tornou um grande avanço para a sociedade, visto que ela, pode abrir novos horizontes em diversas áreas. Como disse Oshima (2016), a realidade virtual pode ser incorporada inclusive na educação. Seu principal foco sempre foi abrir barreiras, criando um mundo alternativo onde tudo fosse possível e isso o torna uma ferramenta indispensável.

Nas aulas de informática, por exemplo, sua tecnologia seria usada constantemente. O que seriam apenas testes e teorias passaria a se tornar algo novo, ouvir as explicações enquanto observa como se faz na prática e cria algo do seu próprio jeito. Simulações de programas em RV entrariam nas mentes dos alunos de uma forma diferente, mais interativa do que qualquer outra. Usar uma tecnologia revolucionária para influenciar jovens a criar tecnologias da sua própria maneira, este é um conceito inimaginável e indispensável.

Porém, conforme foi demonstrado através da pesquisa, percebeu-se que ainda existe uma grande resistência de alguns para a mudança das aulas para esta solução tecnológica. Com a medida que os custos de soluções em RV forem se tornando mais acessíveis ao grande público e a tecnologia for sendo aplicada, aos poucos e de forma controlada nas escolas, a RV pode-se tornar a solução para complementar a aula tradicional, servindo como uma ferramenta a mais a ser utilizada pelo docente em sala, complementando o ensino em sala.

\section{Referências Bibliograficas}

Afonso, Germano Bruno; Martins, Caroliny Capetta; Katerberg, Luciana Poniewas; Becker, Thiana Maria; Dos Santos, Vanessa Carla e Afonso, Yuri Berri. (2020). Potencialidades e Fragilidades da Realidade Virtual Imersiva na Educação. Revista Saberes, volume 15, número 34, Brasil (Pp. 1-20). Recuperado de: https://www.uninter.com/intersaberes/index.php/revista/article/download/1800/414393

Aureliano Júnior., Maurício José; Mendonça, Diego Cézar Monteiro de.; Leite, Anna Paula Martins (2019) Uso da Realidade Virtual e da Realidade Aumentada como ferramentas para aprendizagem. Jornada de Linguagens, Tecnologia e Ensino, volume 2, Brasil, (Pp. 115122). Recuperado de: http://www.lite.cefetmg.br/wpcontent/uploads/sites/114/2019/10/11 UsoRA AurelianoJunior.pdf

Babbitt, Beatrice C.; Usnick, Vanessa. (1993). Hypermedia: A vehicle for connections. Arithmetic teacher, Volume 40, Estados Unidos, Pp. 430-432. Recuperado de: https://www.jstor.org/stable/41195438

Bolfarine, Heleno; Bussab, Wilton O. (1994) Elementos de amostragem, Editora Edgard Blücher, Brasil. 
Cisco. (2018) Simulador de Manutenção de Micro. Recuperado de https://semeandociencia.wordpress.com/2014/12/14/simulador-online-de-montagem-decomputador-recomendo/

Dores, Aretemisa R.; Barbosa, Fernando; Marques, António; Carvalho, Irene P.; De Souza, Liliana e Castro-Caldas, Alexandre. (2012). Realidade Virtual na Reabilitação: Por Que Sim e Por Que Não? Uma Revisão Sistemática. Acta Med Port; volume 25, Portugal (Pp. 414-421). Recuperado de https://core.ac.uk/download/pdf/143404282.pdf

Filho, Paulo de Sá; Dias, Raqueline da Silva. (2019). Realidade virtual e aumentada: Uma metodologia ativa a ser utilizada na Educação. Revista Com Censo: Estudos Educacionais do Distrito Federal, volume 6, n. 4, Brasil (Pp. 94-101). Recuperado de: http://www.periodicos.se.df.gov.br/index.php/comcenso/article/view/741

Giassi, Maristela Gonçalves; Ramos, Mariana Colombo. (2016) Tecnologias da Informação e Comunicação no Ensino e Aprendizagem de Ciências. Revista Dynamis, volume 22, n. 2, Brasil (Pp. 52-62). http://dx.doi.org/10.7867/1982-4866.2016v22n2p52-62

Kochhann, Luiz Eduardo. (2019). Realidade virtual acelera aprendizagem em sala de aula. Recuperado de: https://desafiosdaeducacao.grupoa.com.br/realidade-virtual-aprendizagem/

Lockwood, David (2004), Evaluation of virtual reality in Africa, an educational perspective. United Nations Educational, Scientific and Cultural Organization, volume 1, número 46, França. (Pp. 1 - 46). Recuperado de: http://www.naledi3d.com/Archives/Articles/Evaluation $\% 20$ of $\% 20$ Virtual $\% 20$ Reality $\% 20 \mathrm{i}$ $\underline{\mathrm{n} \% 20 \mathrm{Africa} . \mathrm{pdf}}$

Martini, Augusto, (2001) A máquina está a serviço de quem? Revista BITS, volume 1, número 7 , Brasil. (Pp. 6). Recuperado de: https://asimplicidadedascoisas.wordpress.com/2013/09/06/paulo-freire-a-maquina-esta-aservico-de-quem/

Montero, Edna Frasson de Souza; Zanchet, Dinamar José. (2003). Realidade Virtual e a Medicina. Acta Cirúrgica Brasileira, volume18, número 5, Brasil (Pp. 489-490).

Multilaser. (2019) Óculos 3D. Recuperado de: https://www.multilaser.com.br/oculos-realidadevirtual-warrior-js080/p

Oliveira, Eleilde de Souza; Freitas, Tatiane Cantanhede; Souza, Marliane Ribeiro de; Mendes, Nilteane Conceição da Silva Gomes Mesquita; Almeida, Tiago dos Reis; Dias, Luciana Cutrim; Ferreira, Aline Larissa Mota; Ferreira, Ana Paula Mota (2020). A educação a distância (EaD) e os novos caminhos da educação após a pandemia ocasionada pela Covid-19. Brazilian Journal of Development, Volume 6, Número 7, Brasil (Pp. 52860 - 52857). https://doi.org/10.34117/bjdv6n7-799

Oshima, Flávia Yuri. (2016) A realidade virtual já frequenta escolas públicas brasileiras: O desafio é usá-la de modo a facilitar o aprendizado dos alunos. Recuperado de: https://epoca.globo.com/ideias/noticia/2016/01/realidade-virtual-na-sala-de-aula.html

Pereira, Ivo e Nogueira, Nuno. (2018) Realidade Virtual. Recuperado de: http://web.ist.utl.pt/ist170613/

Ramos, Patrícia Edí. (2019) O professor frente as novas tecnologias de informação e comunicação. Recuperado de: http://www2.seduc.mt.gov.br/-/o-professor-frente-as-novastecnologias-de-informacao-e-comunicac-1

Renaissance Hotels. (2020) Renaissance New York Times. Recuperado de: http://renaissancehotels.marriott.com/renaissance-new-york-times-square-hotel

Ribeiro, Jefferson; Lopes, Mauricio Capobianco (2019), Uso de tecnologias digitais e ambientes virtuais: um estudo com professores e alunos de uma escola estadual de Santa Catarina. Revista de Sistemas e Computação, Volume 9, Número 2, Brasil (Pp. 319-325). Recuperado de: https://revistas.unifacs.br/index.php/rsc/article/view/6428 
Wadhwa, Naman; Khatak, Sunita e Poonam. (2020). Online versus Offline Mode of Education Is India ready to meet the challenges of Online Education in lockdown? Journal of the Social Sciences, volume 1, n 48, Kwait (Pp. 404-413). Recuperado de: https://www.researchgate.net/publication/342946003 Online versus Offline Mode of E ducation -Is India ready to meet the challenges of Online Education in lockdown

Ying, Li; Jiong, Zhang; Wei, Sun; Jingchun, Wang e Xiaopeng, Gao (2017), VREX: Virtual reality education expansion could help to improve the class experience (VREX platform and community for VR based education), 2017 IEEE Frontiers in Education Conference (FIE), Volume 1, Estados Unidos, (Pp. 1-5). Recuperado de: https://ieeexplore.ieee.org/document/8190660

Zampier, Lucinéia. (2016). Simulador Educacional como ferramenta de apoio em aulas de ciências. Os desafios da escola pública paranaense na perspectiva do professor PDE, editora Secretaria de Educação do Governo do Estado do Paraná, volume 2, Brasil. 